\title{
Relation of Receptive Field Size and Salt Taste Responses in Chorda Tympani Fibers during Development ${ }^{a}$
}

\author{
CHARLOTTE M. MISTRETTA, ${ }^{b}$ TAKATOSHI NAGAI, \\ AND ROBERT M. BRADLEY \\ Department of Oral Biology \\ School of Dentistry and \\ Center for Nursing Research \\ University of Michigan \\ Ann Arbor, Michigan 48109
}

During development nerve fibers must establish precise connections with sensory organs. For example, in the adult mammal a single chorda tympani nerve fiber innervates receptive fields on the tongue that contain from one to several fungiform papillae and associated taste buds. However, there has been no developmental study to determine how taste receptive fields are established. We hypothesized that previously observed differences in development of taste responses to various salts ${ }^{1}$ might relate to development of receptive fields. Therefore, the size and chemical response properties of receptive fields for single chorda tympani nerve fibers in sheep fetuses, perinatal animals, and lambs were determined.

Seventy-four fibers were studied in $\mathbf{4 4}$ animals from three age groups: fetuses about 130 days of gestation (term $=147$ days); perinatal animals (about one week before or after birth); lambs (about one to three months postnatal). A single chorda tympani fiber was dissected and the tongue was stimulated with $0.5 \mathrm{M} \mathrm{NH}{ }_{4} \mathrm{Cl}, \mathrm{NaCl}$, and $\mathrm{KCl}$ to record salt taste responses. Then individual fungiform papillae were stimulated electrically with 5 microamps anodal current from a fine platinum probe to determine number of papillae innervated by the fiber.

There was a broad range of receptive field sizes across age groups: for fetuses the range was 3 to 40 papillae per field, mean $(S D)=13(10)$; for perinatal animals the range was 1 to 33 papillae, mean $(S D)=15(9)$; for lambs the range was 2 to 29 papillae, mean $(S D)=11(7)$. There was a significant difference in receptive field size across age groups with a median test $(p<0.10)$, and posttests indicated that lamb fields were smaller than perinatal fields. Not only were small fields observed more frequently in fibers in older animals, but also there was an increase in the proportion of fibers that responded with highest frequency to $\mathrm{NaCl}$ compared to $\mathrm{NH}_{4} \mathrm{Cl}(p=0.06)$. Furthermore, receptive field size correlated negatively with the $\mathrm{NaCl}: \mathrm{NH}_{4} \mathrm{Cl}$ response ratio. That is, smaller receptive fields had higher frequency

\footnotetext{
${ }^{a}$ Supported by National Science Foundation Grant BNS 83-11497 to CMM and RMB.

${ }^{b}$ Address for correspondence: Dr. Charlotte Mistretta, Department of Oral Biology, School of Dentistry, University of Michigan, Ann Arbor, MI 48109.
} 
responses to $\mathrm{NaCl}$ than to $\mathrm{NH}_{4} \mathrm{Cl}(p=0.05)$. Receptive field size correlated positively with $\mathrm{NH}_{4} \mathrm{Cl}$ and $\mathrm{KCl}$ response frequencies $(p=0.01)$.

These results demonstrate that there is already extensive branching of peripheral taste nerve fibers in fetuses providing innervation for large and small receptive fields. However, fibers with small receptive fields are encountered more frequently in older animals, and these tend to be more responsive to $\mathrm{NaCl}$ than other salts. This suggests a developmental reorganization of peripheral innervation with possible reduction of fiber branching in some large receptive fields, or an addition of fibers that innervate small, Na-responsive receptive fields.

\section{REFERENCE}

1. Mistretta, C. M. \& R. M. BRADley. 1983. Neural basis of developing salt taste sensation: Response changes in fetal, postnatal, and adult sheep. J. Comp. Neurol. 215: 199-210. 